\title{
Design and Application of a Situation Simulation Technology in Financial Teaching
}

\author{
https://doi.org/10.3991/ijet.v13i07.8793 \\ Jingsheng Li \\ Luoyang Institute of Science and Technology, Henan, China \\ ljsheng200821@21cn.com
}

\begin{abstract}
In the current financial instructional design, the current technical means can only solve the theoretical problems such as "what" and "why", and it cannot solve the practical problem of "how to do it". To solve this problem, the situation simulation technology was used to financial teaching, and the overall design of experimental teaching system was achieved according to the real situation and data of sample companies. The system focused on the design of the accounting system for one of the two subsystems. It not only included the design of traditional accounting and account systems, and the design of accounting services, but also enriched the design of accounting policies and accounting methods, as well as role-playing design. In particular, the accounting ethics projects, emergencies and coordination relationships were added, focusing on the training of students' judgment ability, coordination ability and innovation ability. The practice showed that situation simulation technology can achieve the experimental operating conditions and can solve the practical problem of "how to do it". To sum up, this experimental teaching has certain operability.
\end{abstract}

Keywords—Situation simulation; financial teaching; accounting; design

\section{$1 \quad$ Introduction}

If the birth of accounting experiment teaching is passive, its development is initiative. Accounting experiment teaching in China started in 1980s, and entered the stage of comprehensive construction after 1990s.

Based on the related theories of the accounting situation simulation experiment teaching system, with the help of the existing theoretical knowledge and the actual needs of teaching, this paper designs the comprehensive simulation experiment teaching scheme of the financial situation of Northeastern University. According to the proposed experimental design scheme, the related situation of the sample enterprises are investigated, and the information and materials required for the establishment of the experimental teaching system are collected. Based on real material and data, we put forward the overall design idea, objectives and principles of financial scenario simulation teaching. Then, by establishing the experimental tutorial and experimental operation instruction book, we link all experiments to form a complete experimental 
teaching system. Finally, the hardware and software conditions of the teaching system are discussed, so that the experimental teaching is operable.

\section{$2 \quad$ Literature Review}

The scholars Chen and others believed that the accounting experiment teaching enabled each student to complete an accounting cycle through the teacher's guidance in the shorter time of the accounting simulation experiment [1]. However, scholar Chen held that, due to the lack of profound understanding of the function of experimental teaching, the experimental content was limited to verifying experimental and technical training. The content of the data is simple and the level of the experiment is lower [2]. In the process of experiment, students do experiments according to the prescribed methods and steps, and students are completely in a passive position. There are a lot of experiments, but students do not analyze problems, and have no sense of innovation. The researcher Shi thought that most of the existing accounting experimental teaching systems had the above problems, which restricted the improvement of the quality of experimental teaching and did not adapt to the requirement of the knowledge economy for the training of talent quality [3].

Experiment plays a very important role in the training of science and engineering talents. The famous scholar Li said, "The experiment is the heart of a modern university, and the importance of the laboratory does not emphasize too much" [4]. The scientist Ding Zhao raised the expectation when he won the Nobel Prize: the acquisition of the Nobel Prize could improve the Chinese understanding of the experiment and pay attention to the importance of the experiment. Although the two scientists are concerned with the science, their views are also applicable to social sciences, especially accounting with strong technical and operational features.

The scholar Peng thought that the accounting experiment teaching should not only cultivate the students' operational skills and improve the practical ability, but also exercise students' comprehensive use of knowledge and mobilize the existing knowledge reserves to think, analyze, judge things, grasp the real quality of the accounting work, and cultivate the good spirit of science and creative thinking habit [5].

Scholar Wang put forward that accounting experiment teaching system should include cognitive experiment and verification experiment [6]. The accounting cognition experiment is to acquire the perceptual knowledge of accounting work, understand the content of accounting work, make the purpose of learning accounting clear, and stimulate the interest of learning. The accounting verification experiment is to use the knowledge of accounting to calculate and analyze all kinds of economic business, to master and use all kinds of accounting methods, and to improve the practice ability of accounting practice.

From July 19 to 22, 1994, the first "Seminar on Accounting Experiment Teaching" of National College was held at the Tianjin Institute of Finance and Economics. There were 45 representatives from 25 colleges and universities, and 16 papers were submitted. The seminar focused on the issues related to the teaching of accounting experiments in the school, and set up a "Seminar on Accounting Experiment Teaching" and 
decided to hold a seminar every two years. Through various seminars, the experience of accounting experiment teaching was exchanged, the understanding of accounting experiment teaching was improved from the strategy of accounting education, and the development of accounting experiment teaching was promoted.

\section{$3 \quad$ Methodology}

\subsection{The idea, objectives and principles of the overall design of financial} situation simulation experiment teaching system.

The experimental system includes two subsystems of accounting system and financial management system. Moreover, the two systems are used as the center for the establishment of the necessary internal and external environment to enable students to experience the highly simulated experimental situation and obtain important perceptual knowledge. In the experiment, the accounting system and the financial management system share a set of data, that is, a series of accounting vouchers, accounting books, accounting statements and other accounting data formed by a certain industrial enterprise financial accounting simulation experiment. The ultimate goal is to make financial analysis, financing management, investment management, and assets management and so on. In the operation of the system, the two subsystems are interdependent and complementary to each other. Each experiment is linked together so that the students can not only further consolidate the knowledge of the academic accounting theory, but also understand the position of the financial department, understand the responsibilities of different posts, and the whole process of dealing with the financial business, thus truly mastering the current situation of accounting and management.

The simulation experiment, which is basically the same from the environment situation to the practical content and the financial department of the sample enterprise, is used to simulate the post responsibility and the business process experiment environment. As a result, it makes the students feel in the highly simulated experimental environment and practical employment, and improve the effect of the experiment.

The principles of overall design include the principle of high emulation, the principle of combining comprehensiveness and importance, the principle of combining typicality and practicality, the principle of operability, the principle of coordination of subsystems, the principle of business system expansion, the original principle of combining business handling with relationship handling, and the principle of studentcentered.

\subsection{Overall design content of financial situation simulation experiment teaching system}

This experiment selects the Shenyang BP Magnetic Resonance Technology Limited Company as the sample of the experimental teaching simulation enterprise. The company is formed by the NS-PH Medical Equipment Limited Liability Company 
and the Institute of Physics of the Chinese Academy of Sciences. It is a high-tech production enterprise which produces magnetic resonance medical equipment. The scale of the company is at the middle level and is the general taxpayer enterprise. The enterprise has a more sound organization structure, the products produced have the representativeness of the industrial enterprise, and the financial department mainly set up the positions of finance minister, cashier, accounting and financial management. There are 5 accountants in total, which basically meet the requirements of comprehensive experimental teaching system for financial scenarios needed to be established. For the lack of information to be investigated, we need to refer to the specific settings of NS-PH Medical Equipment Co., Ltd. to make up for it.

After determining the sample enterprise, the specific situation of the enterprise is investigated. It mainly include the basic information of the enterprise registration, the organizational structure of the enterprise and the responsibilities of various departments, as well as the production process flow of the product, the business process of the purchase and sale, the situation of the business unit and the job division and responsibility of the finance department. It also contains the setting of the financial department scene, the supplies and finance for the office of the finance department, the accounts processing procedure, the daily economic business of the finance department, the relations between the finance department and the other departments within the enterprise, and the business of the finance department and the other units outside the enterprise, to prepare for the design of the simulation experiment.

On the basis of basic understanding, we refer to the work situation of the financial department of the Shenyang BP Magnetic Resonance Technology Limited Company, and the related work of the NS-PH Medical Equipment Limited Liability Company. After carefully selecting and removing the nonstandard business, it selects the representative economic business with the daily occurrence as the industrial production enterprise and not daily happening but typical business operations, which are used for experimental teaching. In order to meet the needs of experimental teaching, a reasonable and practical design is made according to the actual situation of the sample enterprises for the economic businesses that sample enterprises do not involve, but the type that should be mastered by the students majored in accounting. In addition, in order to achieve realistic effect, it is necessary to train students' actual working ability, and select the actual incidents and coordination events in the daily work of the sample enterprise financial department, and carry out the design used for experimental teaching.

As a new production and manufacturing enterprise, this system designs it as a complete organization institute, including management department, production department, sales department, and research and development department, as shown in Figure 1. 


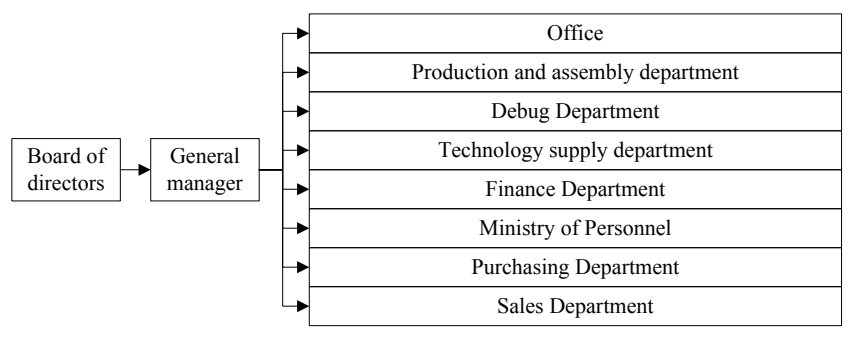

Fig. 1. The organizational structure of enterprises

Shenyang BP Medical Technology Co., Ltd. mainly produces two kinds of MRI products, namely magnetic resonance 1 and magnetic resonance 2 , and the production cycle is 5 months. Its production process is shown in Figure 2.

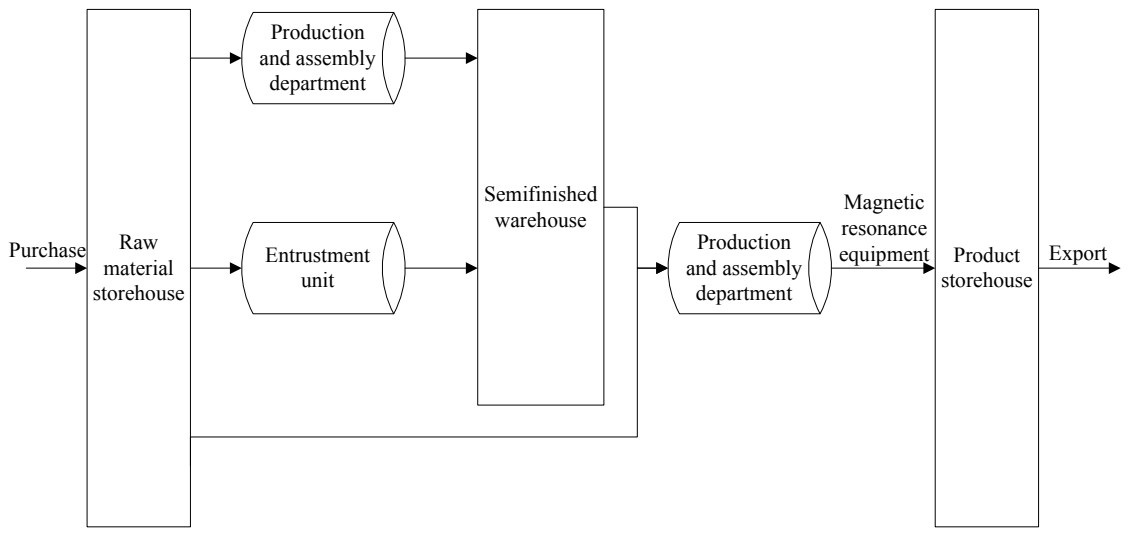

Fig. 2. Production technical process

The comprehensive financial simulation experiment teaching system includes two subsystems: accounting system and financial management system. Accounting subsystem is mainly responsible for the daily business accounting, compiling account vouchers, and then registering accounting books according to the original voucher, and finally compiling the accounting statements to simulate the duties of the enterprise cashier and accounting. Additionally, it includes emergencies, relationship coordination and accounting moral judgment design. The design of the financial management subsystem mainly involves the analysis of the financial situation of the enterprise, the analysis of investment and financing, the cost, the sales and the forecast of the profit and other daily financial management modules. Moreover, it also includes the modules of the financial relations coordination of the internal and external departments and the professional judgment experiment.

Situation setting is the premise and foundation to simulate experiment teaching. It is necessary to design the experimental situation according to the contents and characteristics of the experiment, fully embody the art of teaching and stimulate the students' learning motivation. The situation simulation design covers four aspects, including 
the object scene design, the business situation design, the accounting moral judgment, the unexpected events and the coordination relationship design, and the role playing design.

According to the division of responsibilities, the finance department can be divided into two branches, accounting group and financial management group. According to the real situation of enterprises, combined with the needs of experimental teaching, 1 financial management post is added on the basis of post setting in the financial department of sample enterprises.

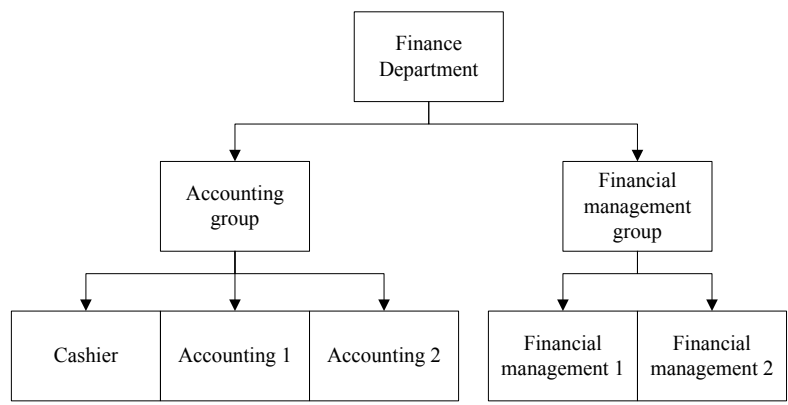

Fig. 3. Financial department organizational structure

The structure layout of the simulation finance department should imitate the layout of the real enterprise finance department, realize the simulation of the experimental environment, and make the students experience the real situation of the work of the financial department of the enterprise, and have the feeling of being in the situation. The layout structure is shown in Figure 4.

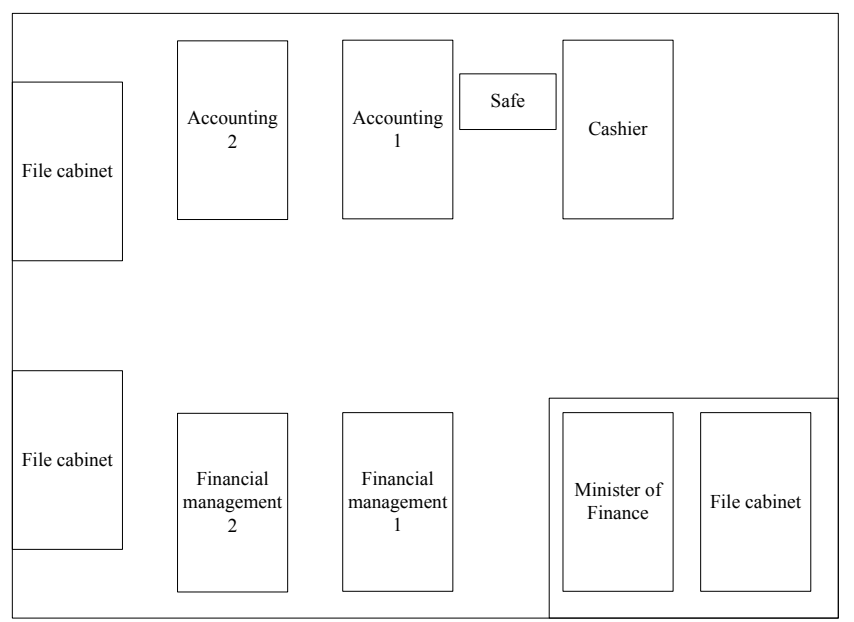

Fig. 4. Finance department planar structure 


\section{$4 \quad$ Results and discussion}

\subsection{Overall design of the accounting subsystem}

The design of the accounting subsystem is combined with the teaching of theoretical knowledge to make the experiment content to cover the main courses of the accounting profession to the maximum extent, and to remove the experimental contents which are inconsistent with The Accounting Standards of the Enterprise, to establish a new experimental project to reflect the international accounting practice, and to construct a scientific accounting experiment system. The design of the accounting subsystem is different from the traditional accounting simulation experiment and the situation simulation experiment model is established. On the basis of good accounting, accounting ethics, unexpected events and coordination relationship are added to make the students not be restricted by the existing professional skills, and learn to put forward questions and ideas and train students' ability to think, analyze, judge and solve problems, as well as the ability to think and innovate independently. In addition, students are required trying to derive an ideal state from these problems and ideas.

Build a highly simulated experimental scene, and on the basis of the confirmatory experiment, increase the exploratory experiment, comprehensively improve the students' moral concept, coordination and creativity, and construct a scientific, interactive and comprehensive manual operation accounting experimental teaching system.

The design principles of the accounting subsystem are systematic principle, comprehensive principle, the principle of combining comprehensiveness and typicality, the principle of combining daily business with unexpected events, and the principle of combining verification and exploration.

In the financial department, the duty of the accounting group is mainly the accounting of the economic business, the registration of account books and the compilation of various reports. According to the amount of accounting business designed, in terms of the accounting group post operation, but the setting of the post does not require one person for one post, but more positions for one person, so that every student who carries out the experiment can get more contact with the accounting practice and master the accounting process of various kinds of economic business. In addition, students will be planned for the rotation experiment, making students fully familiar with the accounting business and improving the quality of business. The specific setting of the post of accounting group is shown in Figure 5.

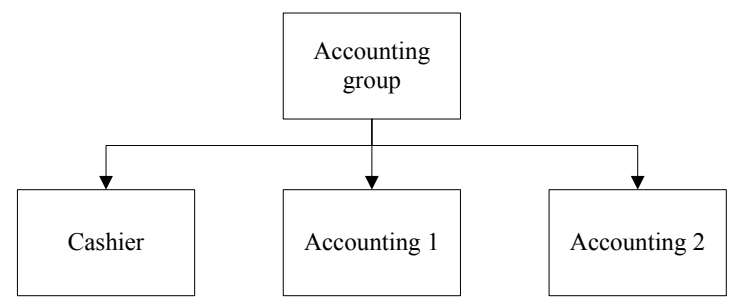

Fig. 5. Accounting group organizational structure 
In the accounting teaching system, in addition to the role playing of the accounting group in the financial department, teachers and students are required to play a specific role in the appropriate time to achieve the effect of teaching simulation and to make the simulation experiments operating truly.

Within the enterprise, the accounting work will be in contact with other departments. In the purchasing business of materials, the students are arranged to act as the staff of the purchasing department and by virtue of the material receipt and the supplier invoice, the accounting team is informed of the payment. In the material collar business, the students are arranged to act as the custodian of the material bank, and the quotas or the documents are given to the accounting unit as the original voucher to register the accounts receipts. In the service of the processing material, the student should be played as the depository of the material bank, and the accounting unit is registered as the original voucher in the accounting unit. In the sales business, the students should be played as the staff of the sales department, and the output of the finished goods is given to the accounting unit to be used as a special issuing ticket for value added tax (VAT), and to follow and supervise the clients to the finance department for payment procedures. In personal loan and reimbursement business, the student or instructor acts as the role of a department staff, and according to the needs of the business design, the loan or reimbursement cost of the accounting unit is required.

Outside the enterprise, accounting mainly has business contacts with banks and tax authorities. In the banking institution, students can be arranged to act as the bank counter, and the students of the accounting group go to the bank to deal with the related business; in the tax authorities, the instructor teacher acts as staff of accounting department and the accountant go to the tax authorities to pay taxes.

\subsection{Selection and design of accounting policy and accounting method}

The design of accounting policy and accounting method is basically consistent with the prototype of a sample enterprise, so as to achieve the effect of simulation. Only the accounting policies that are not involved in the sample enterprises, or the accounting policies which are used by the sample enterprises, but the methods are very special and do not represent the universality, and the accounting policies which are not consistent with the new accounting standards for enterprises are given appropriate additions or modifications, so that the experimental teaching has the common practical significance.

The accounting process of categorized accounts summary is completed every ten days, and the flow chart is shown in Figure 6. 


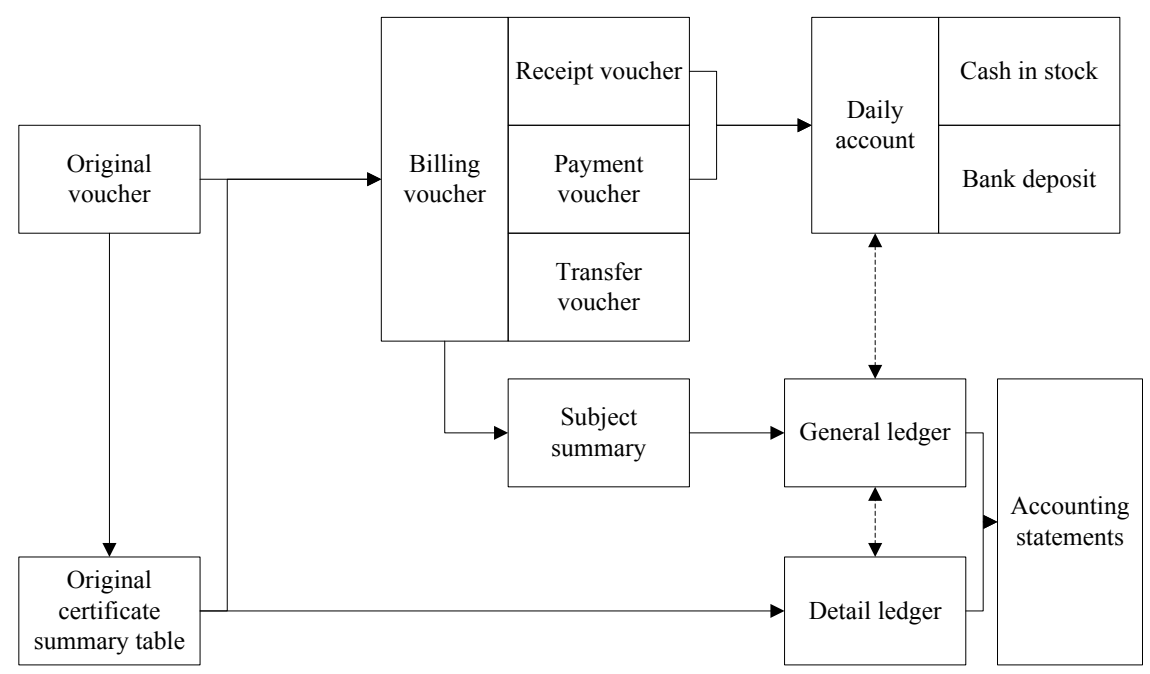

Fig. 6. Account treatment procedure

The method of product cost calculation adopts the batch method, the indirect cost of the production and assembly department sets up "manufacturing cost" account, and the indirect cost of the debugging department is not specially set up to account. The fee cost accounting process is shown in Figure 7.

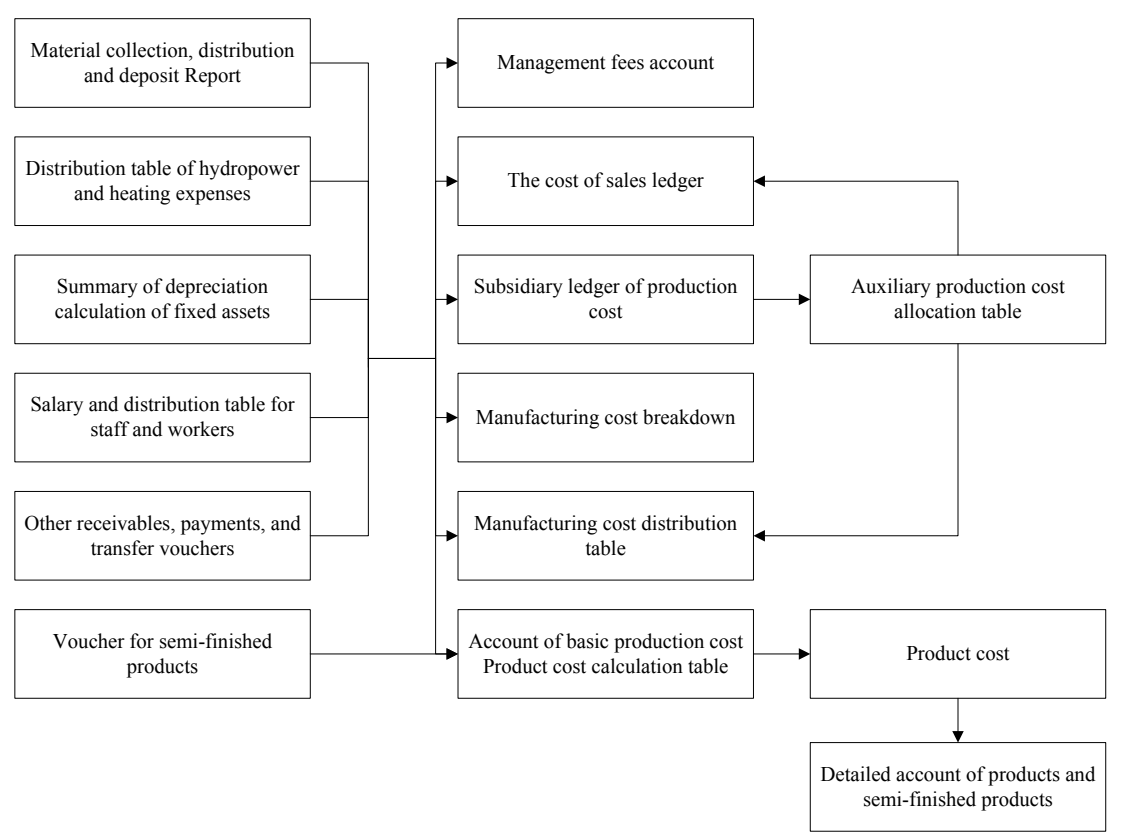

Fig. 7. Product cost accounting procedures 
For the main business of the industrial enterprise, the basic business process is given in the experiment, including the material purchase business process, the material collar business procedure, the material issuing business procedure, and the product sales procedure, so that the students can have a clear understanding of the operation of the enterprise and complete the experiment project better. Among them, the material purchase business process flow is shown in Figure 8, and the material collar business procedure is shown in Figure 9.

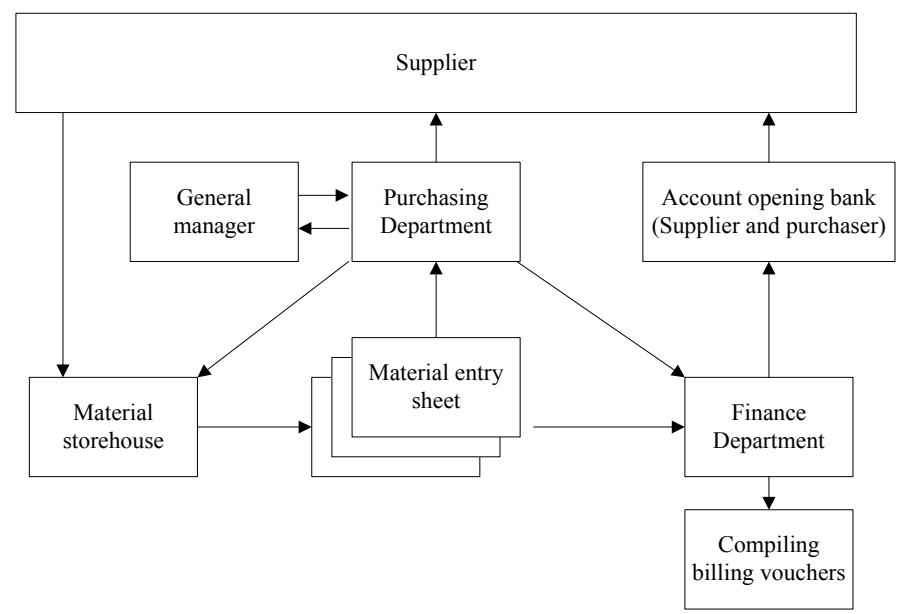

Fig. 8. Material purchases business process

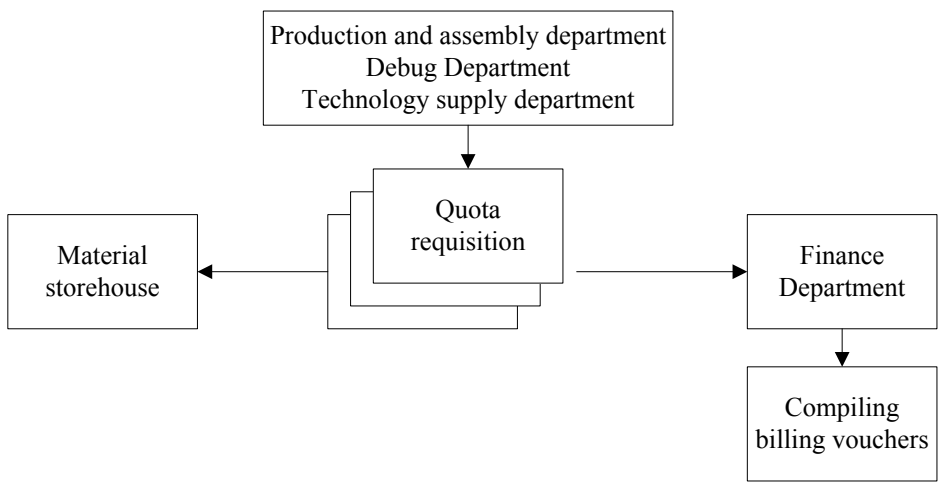

Fig. 9. Material leads business process

\subsection{Design of accounting moral project}

Accounting is a value activity, often facing professional temptation and moral conflict. The study stage at school is a period of initial formation of students' moral concept and right and wrong evil judgment standard. It is an important link to accept accounting moral education and has a great influence on the future accounting work. 
Therefore, the students' accounting moral project are designed and exercised in the experiment, which can be used to examine the students' ability to hold the principle and lay a good foundation for their future work. Based on the above considerations, a "violation reimbursement experiment" is designed in the system.

Due to the fact that the experimental items involve the contents that the roles are inappropriate to be public, we encourage the experimenters to perform experiments one by one. A student holds the post of auditor in the finance department and a tutor is a member of a department.

Instructors should be flexible according to the situation in the process of experiment. In the process of reimbursement, it is natural and ordinary to mix the original documents which do not conform to the requirements in other credentials, so it has a certain degree of concealment. It is necessary to prepare for the inspectors to find out the vouchers. If they are not found, they will be reimbursed smoothly, and if they are found, the auditors should be reimbursed as much as possible with a talk or a request.

For the experimenters, that is, the examination of accounting auditors can be done in different ways, and the instructors should be flexible in terms of master. The instructor can evaluate directly according to the performance of the students, and can also let the students who play other roles comment on the performance of the experimenter, and finally the instructor gives the comprehensive evaluation.

The focus of the examination lies in the experimenter's attitude and the ability to judge the practice, including the seriousness of the experimenter, the ability of the experimenter to discover the original voucher of the violation, the immediate response of the experimenter to the original voucher, the ability of the experimenter to adhere to the original rule in the face of the temptation of the reimbursement personnel, and the handling results of the events by the experimenter and so on.

\subsection{Project design of unexpected events}

According to the principles of typicality, complexity and practicality, we design the simulation experiment situation and perform the role play in terms of the project design of unexpected events. The unexpected events add vitality to the simulation experiment. On the basis of the basic fixed accounting, the events with uncertain factors are added, and the students' ability to handle things, judge and innovate is emphasized.

Accounting work can come into contact with a lot of economic businesses related to money funds. It is a kind of value activity. Therefore, there will be sudden events related to "money". Accounting transactions and matters themselves as well as their solutions will have great uncertainty and selectivity. In the process of operation, it is necessary to deal with all kinds of complex interpersonal relationship, which is a test for accountants' contingency. The design of "manager's request for abnormal account entry" is to train students' adaptability and judgment ability, and improve their skills in dealing with accidents.

Due to the fact that the experimental items involve the contents that the roles are inappropriate to be public, we encourage the experimenters to perform experiments 
one by one. A student holds the post of auditor in the finance department and a tutor is a member of a department.

Instructors should be flexible according to the situation in the process of experiment. In the process of reimbursement, the manager should give the auditor the pressure of reimbursement, take a commanding attitude to the auditors, and test the students' ability to cope with them and whether they can stick to the principles.

\subsection{Coordination relationship project design}

The design of a coordinated relationship project follows the principles of pertinence, typicality and practicality, so that the teaching will improve the interest of the students and make the experiment more operable. The coordination relationship project enriches the content of the simulation experiment, enriches the form of experimental teaching, adds the relation handling events, and trains the students' ability to adapt to their creative work and the ability of communication and coordination.

In the actual financial work, the financial department is not isolated, but it is very close and even complicated with other departments in the enterprise. This relationship directly affects the organization structure of enterprises and the formation of the whole system, and directly affects the development of accounting activities and even the survival and development of enterprises. Therefore, coordinating the relationship with other departments is an important part that accountants must always face. Before the accounting students go to work, the students can feel the real events of coordination between the various departments in the enterprise by designing "the experiment on coordination relationship with the other departments in the enterprise", so as to guide the students to establish the concept of modern public relations and cultivate the adaptation ability of the students in their work.

To this end, we design experiment one with one student as cashier, and three to five students acting as other roles in the finance department, and an instructor as a borrower staff.

The borrower staff should flexibly respond to what happens in the experiment. When borrowing, it is necessary to make the whole process hidden so that it is not easy to be identified by cashiers and prepare well for the cashier to find out the budget. If it is not found, a loan is borrowed smoothly; if found, we can take a variety of ways to ask for borrowing, such as talking about the importance of the loan, asking for a loan, or using a tough attitude to explain the importance of the responsibility and the seriousness of the consequences, and asking for a loan.

For experimenters, cashiers' assessment can take different ways. The instructor can evaluate directly according to the performance of the students, and on the basis of the group discussion, the experimenter and other people who are involved in the discussion can be evaluated synthetically.

In accounting practice, the relationship between the accounting department and the outside world, in essence, is the relationship between the enterprise and the outside world, because the accounting department is the spokesman of the enterprise to some extent, reporting to the outside world and explaining the financial situation of the enterprise. Therefore, good public relation between accounting departments and en- 
terprises is very important for enterprises and affects the long-term development of enterprises. And how to coordinate the relationship with the outside world is a challenge for accountants. The tax department is an external organization which is closely related to the enterprise. It has an important influence on the management and development of the enterprise. It is the external unit that the financial department often contacts. Therefore, the "experiment with other units outside the enterprise" is designed in the teaching, and the students' communication and coordination ability can be exercised and the students' actual working ability can be trained.

It is suggested that the way of collective discussion be adopted. Students can analyze their experiments from different angles, elaborate their own views, analyze problems in collective discussion, and propose solutions. Teachers should pay attention to the direction of case discussion, and play a guiding role when necessary.

To this end, we design experiment two with one student acting as a payment manager, and three to five students playing the role of other positions in the finance department, and a tutor as the representative of the supplier.

As a supplier representative, the instructor teacher should have a clear stand and an appropriate attitude and stick to his own correctness. Instructors should flexibly respond to the situation in the process of experiment, guide students to communicate and investigate their coordination ability.

For the experimenters, the assessment of the payable management personnel can take different ways. The instructor can evaluate directly according to the performance of the students, and on the basis of the group discussion, the experimenter and other people who are involved in the discussion can be evaluated synthetically.

\section{Conclusion}

Based on the related theories of the accounting situation simulation experiment teaching system, with the help of the existing theoretical knowledge and the actual needs of teaching, this paper puts forward the overall design ideas, objectives and principles of the comprehensive simulation experiment teaching for financial situation, and highlights the characteristics of the simulation of the situation. On the basis of the overall design, at the same time, the design of the accounting system of one of the two subsystems is emphasized, and the design ideas, objectives and principles of the subsystems are clearly defined. The specific design of accounting policies and accounting methods is carried out, and the design of the accounting moral project, the design of unexpected events and the coordination of the project are also integrated, and training of the judgment ability, coordination and innovation ability of the students is emphasized.

\section{References}

[1] Chen, J., Zhong, L., Wang, C. (2013). Practice of entrepreneurship education in The Virtual Corporation mode. Success (Education), 18: 201-202 
[2] Chen, T. (2013). Application of interactive teaching method in basic courses of mechanical specialty. Educational observation, 6: 111-112

[3] Shi, Y. (2014). Application Research on the purpose of financial reporting. Hebei University, 2: 121-122

[4] Li, R. (2014). The environmental cost control model of Shaanxi coal enterprises. Shaanxi University of Science and Technology, 1:23-24

[5] Peng, J. (2014). LG sewage treatment project financial evaluation research. South China University of Technology, 2: 54-55

[6] Wang, J. (2014). The correlation between environmental information disclosure and cost of equity capital. Beijing Forestry University, 1: 46-47

\section{$7 \quad$ Author}

Jingsheng Li is with the Luoyang Institute of Science and Technology, Henan 471000, China.

Article submitted 23 March 2018. Final acceptance 04 May 2018. Final version published as submitted by the author. 